\title{
DÜBLIN
}

Technological University Dublin

ARROW@TU Dublin

2004-01-01

\section{Printed Planar Monopole Antenna with Electromagnetically Coupled Elements}

\author{
Jonathan Evans \\ Technological University Dublin \\ Francisco Lerma \\ Technological University Dublin \\ Max Ammann \\ Technological University Dublin, max.ammann@tudublin.ie
}

Follow this and additional works at: https://arrow.tudublin.ie/engschececon

Part of the Electrical and Computer Engineering Commons

\section{Recommended Citation}

Evans, J., Lerma, F., \& Ammann, M. (2004) Printed planar monopole antenna with electromagnetically coupled elements. High Frequency Postgraduate Student Colloquium, pp.81-86. 6-7 September, 2004, doi:10.1109/HFPSC.2004.1360358

This Conference Paper is brought to you for free and open access by the School of Electrical and Electronic Engineering at ARROW@TU Dublin. It has been accepted for inclusion in Conference papers by an authorized administrator of ARROW@TU Dublin. For more information, please contact arrow.admin@tudublin.ie, aisling.coyne@tudublin.ie,gerard.connolly@tudublin.ie.

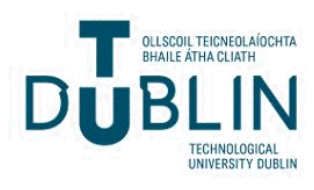




\title{
Printed Planar Monopole Antenna with Electromagnetically Coupled Elements
}

\author{
J.A. Evans, F. Leon Lerma and M. J. Ammann \\ School of Electronic and Communications Engineering, Dublin Institute of \\ Technology, Ireland. \\ e-mail: jonathan.evans@comreg.ie
}

\begin{abstract}
Planar monopole antennas and dual plate antennas have been reported to yield wide bandwidths [1-2]. Printed monopole antennas have previously been shown to be implementable on planar dielectric substrates using low cost microstrip printing techniques [3]. In this paper, the addition of an electromagnetically-coupled element to the printed planar monopole antenna is investigated. While remaining simple to construct, modifications to the electromagnetically-coupled element are shown to reduce the lower edge frequency of the $10 \mathrm{~dB}$ impedance bandwidth by up to $\sim 19 \%(280 \mathrm{MHz}$ at $1.5 \mathrm{GHz})$. The radiation patterns for these antennas are characteristic of monopole antennas - i.e. omnidirectional in the azimuth plane with a null at the zenith - and are consistent within $+/-2 \mathrm{~dB}$ across their useful impedance bandwidths. By optimizing the feed arrangements on these antennas a $10 \mathrm{~dB}$ impedance bandwidth ratio of over $3: 1$ can be achieved. This technique yields the ability to construct a smaller antenna, in comparison to a simple printed planar monopole antenna, for a given frequency range. The antennas considered in this paper operate between 1.3 and $5.5 \mathrm{GHz}$, making them suitable for numerous mobile and portable applications. Measured results are compared to antenna simulations using Transmission Line Modelling.
\end{abstract}

\section{THE PRINTED MONOPOLE ANTENNA}

A $30 \mathrm{~mm}$ square planar monopole element is printed on a $80 \mathrm{~mm} \times 60 \mathrm{~mm} \times 1.5 \mathrm{~mm}$ dielectric substrate (Fig. 1). The substrate used is FR4; a low cost epoxy resin/fiberglass laminate typically used for low frequency PCBs. FR4 has a permittivity of 4.4 and a loss tangent of 0.018 at $2 \mathrm{GHz}$. The metalisation thickness on the board is 35 microns ( $1 \mathrm{oz} / \mathrm{sq}$ foot). A $28 \mathrm{~mm} \times 60 \mathrm{~mm}$ ground plane is printed on the opposite side of the substrate, which stops $2 \mathrm{~mm}$ short of the beginning of the monopole element. The monopole element is fed via a $50 \mathrm{ohm}$ microstrip feed line with a width of $2.46 \mathrm{~mm}$. The feed-line is fed from an end launch SMA connector. The overall board size is $80 \mathrm{~mm} \times 60 \mathrm{~mm} \times 1.5 \mathrm{~mm}$, making it suitable for integration in many mobile and portable devices. The $10 \mathrm{~dB}$ impedance bandwidth of the printed monopole antenna was measured as $1.54 \mathrm{GHz}$ to $3.73 \mathrm{GHz}$ (Fig. 2). 


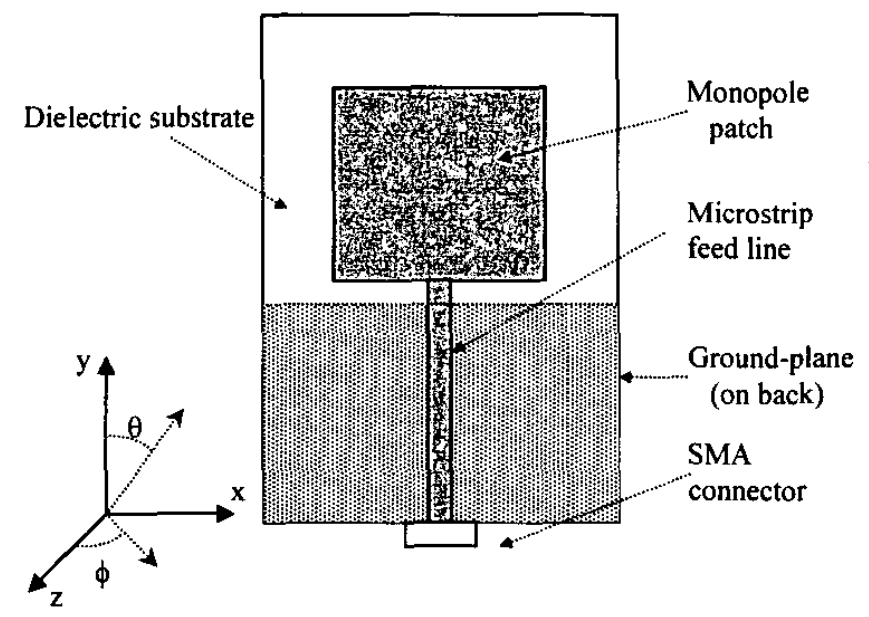

Figure 1: Printed monopole antenna

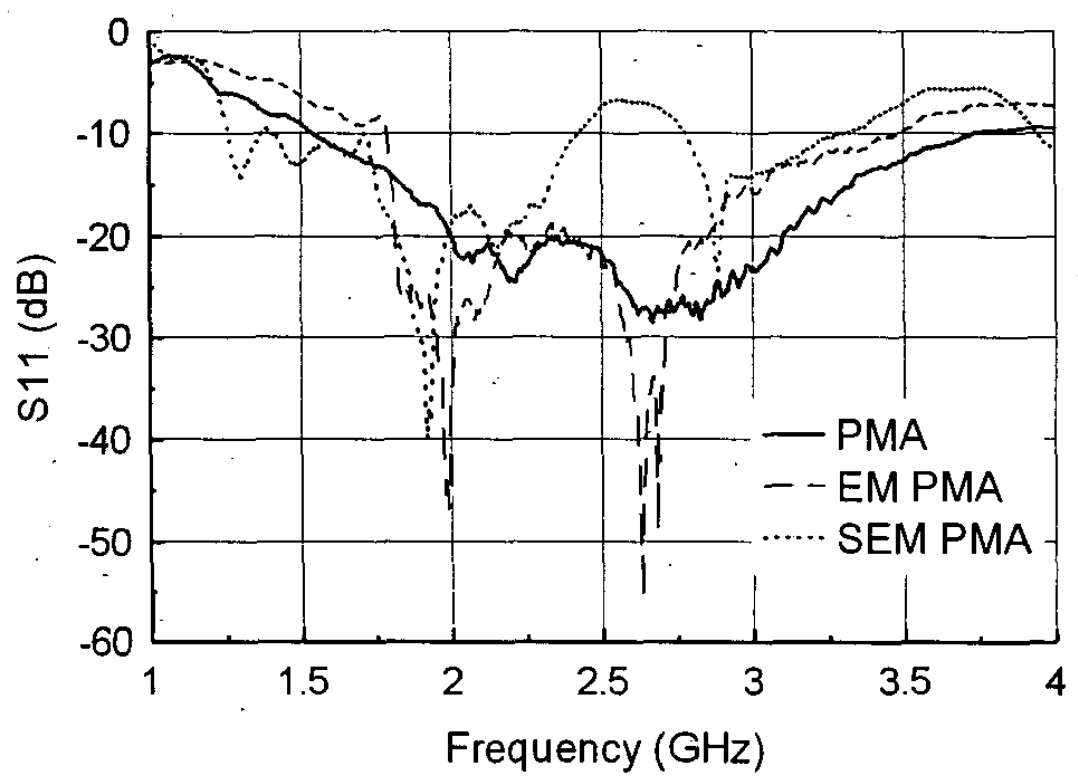

Figure 2: $10 \mathrm{~dB}$ impedance bandwidths for the Printed Monopole Antenna (PMA), the PMA with an electromagnetically coupled element (EM PMA), and the EM PMA with slots cut out of the EM element (SEM PMA).

\section{ELECTROMAGNETICALLY-COUPLED ELEMENTS}

A slotted element is introduced on the opposite side of the dielectric substrate and is electromagnetically coupled to the main monopolar element (Fig. 3). The EM coupled element is also $30 \mathrm{~mm}$ square and is located directly below the main monopolar element. The impedance bandwidth of the antenna can be enhanced by removing slots from the EM coupled elements of various geometries. The addition of 
an EM element alone actually decreases the $10 \mathrm{~dB}$ impedance bandwidth of the antenna. Single slot and dual slot arrangements were investigated with various slot sizes and orientations. The dual slot design was found to yield the greatest reduction in lower edge frequency. Slot sizes were $5 \times 20 \mathrm{~mm}$.

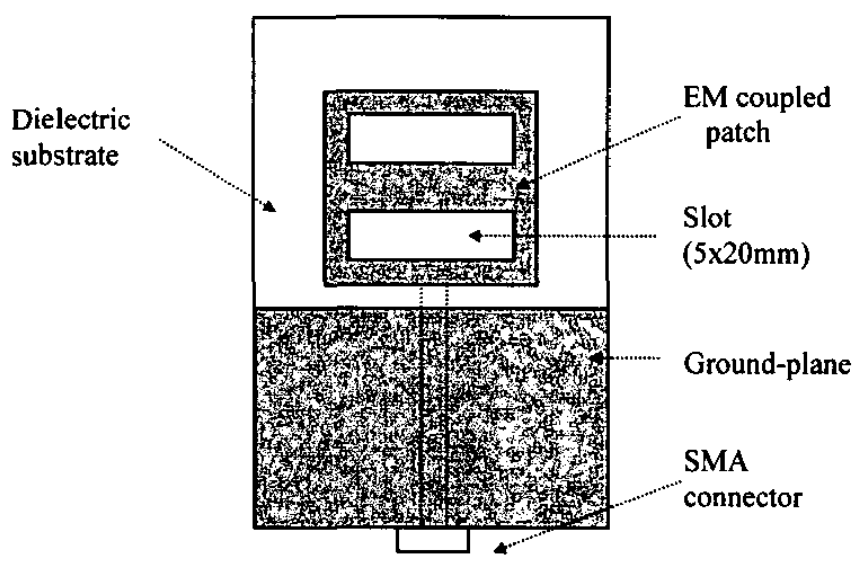

Figure 3: Printed monopole antenna with EM-coupled slotted plate (view from back).

The effect of the EM couple element and the application of different sized slots have significant effects on the $10 \mathrm{~dB}$ impedance bandwidth of the antennas. The optimum design, in terms of reducing the lower edge frequency, was found to be for the double slotted EM element described above. This antenna yielded two separate $10 \mathrm{~dB}$ impedance bandwidth ranges, from $1.26 \mathrm{GHz}$ to $2.42 \mathrm{GHz}$, and from $2.78 \mathrm{GHz}$ to $3.29 \mathrm{GHz}$ (Fig. 2). This represents a significant reduction in the lower edge frequency of $280 \mathrm{MHz}(-19 \%$ at $1.5 \mathrm{GHz})$, and yields a monopole element is approximately $\lambda / 8$ long.

\section{FEED-POINT OPTIMISATION}

The impedance bandwidth of this antenna can be significantly increased by adjusting the point at which the microstrip feed line joins the monopole element. Offsetting the feed by $5 \mathrm{~mm}$ from the center of the substrate was found to produce the optimum results with an increase in $10 \mathrm{~dB}$ impedance bandwidth of over $75 \%$ up to $1.64-5.5$ $\mathrm{GHz}$ (Fig. 4). This is an impedance bandwidth of over 3:1. 


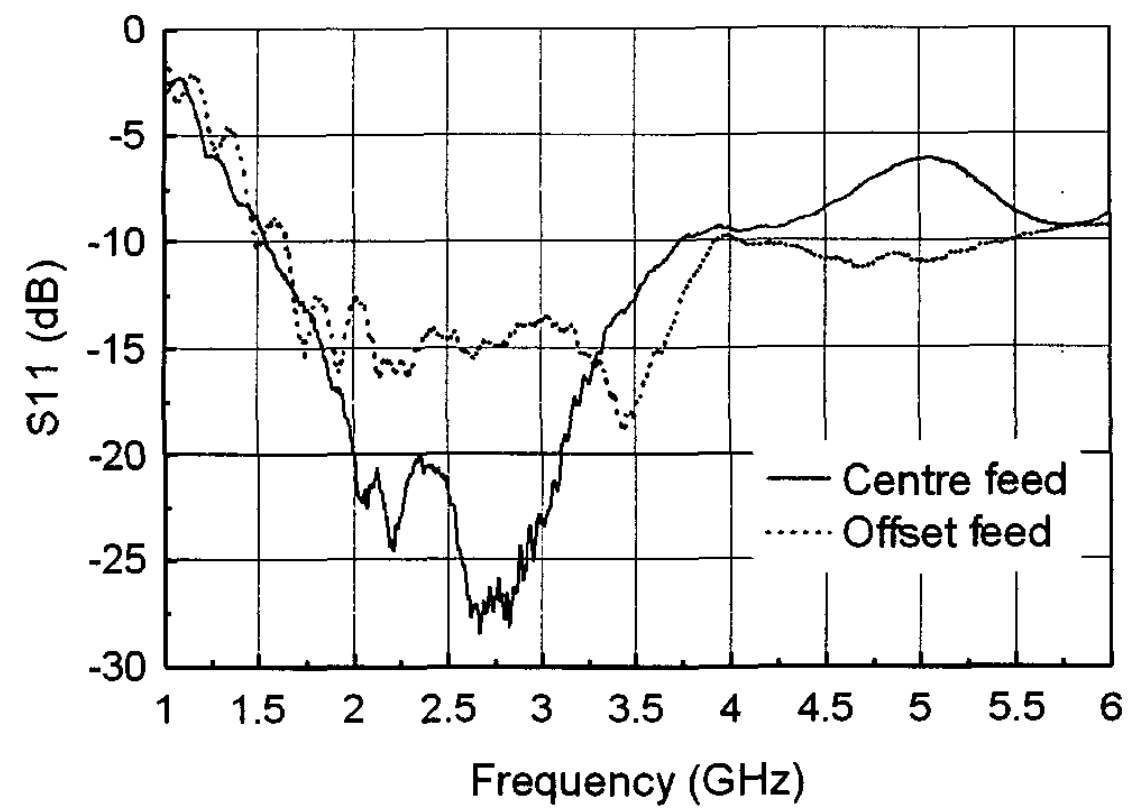

Figure 4: Optimisation of the feed point for the PMA.

\begin{tabular}{|l|l|c|c|c|}
\hline Antenna & \multicolumn{1}{|c|}{ Description } & $\begin{array}{c}\text { 10dB lower } \\
\text { (GHz) }\end{array}$ & $\begin{array}{c}\text { 10dB } \\
\text { upper } \\
\text { (GHz) }\end{array}$ & $\begin{array}{c}\text { 10dB } \\
\text { Bandwidth } \\
\text { (GHz) }\end{array}$ \\
\hline PMA & $\begin{array}{l}\text { Printed square monopole antenna, } \\
\text { center fed }\end{array}$ & 1.54 & 3.73 & 2.19 \\
\hline EM PMA & $\begin{array}{l}\text { PMA with EM coupled square } \\
\text { element }\end{array}$ & 1.64 & 3.52 & 1.88 \\
\hline SEM & $\begin{array}{l}\text { EM PMA with two 5x20mm slots } \\
\text { PMA from EM coupled element }\end{array}$ & $\begin{array}{l}1.26 \\
12.78\end{array}$ & $\begin{array}{l}2.42 \\
13.29\end{array}$ & 1.16 \\
\hline SEM & $\begin{array}{l}\text { EM PMA with single 5x20mm slot } \\
\text { cut from EM coupled element }\end{array}$ & 1.79 & 3.5 & 1.71 \\
\hline PMA (b) & PMA with feed off-set by 5mm & 1.64 & 5.5 & 3.86 \\
\hline
\end{tabular}

Table 1: Printed monopole antennas and their $10 \mathrm{~dB}$ impedance bandwidths.

\section{ANTENNA MODELLING}

The antennas were modeled using transmission line modeling (TLM). Although the simulations typically underestimated the responses of the antennas compared to measured results (Fig. 5), they were useful for optimizing the effects of various geometry modifications to the antenna geometry, such as slot size and feed-point positioning. 


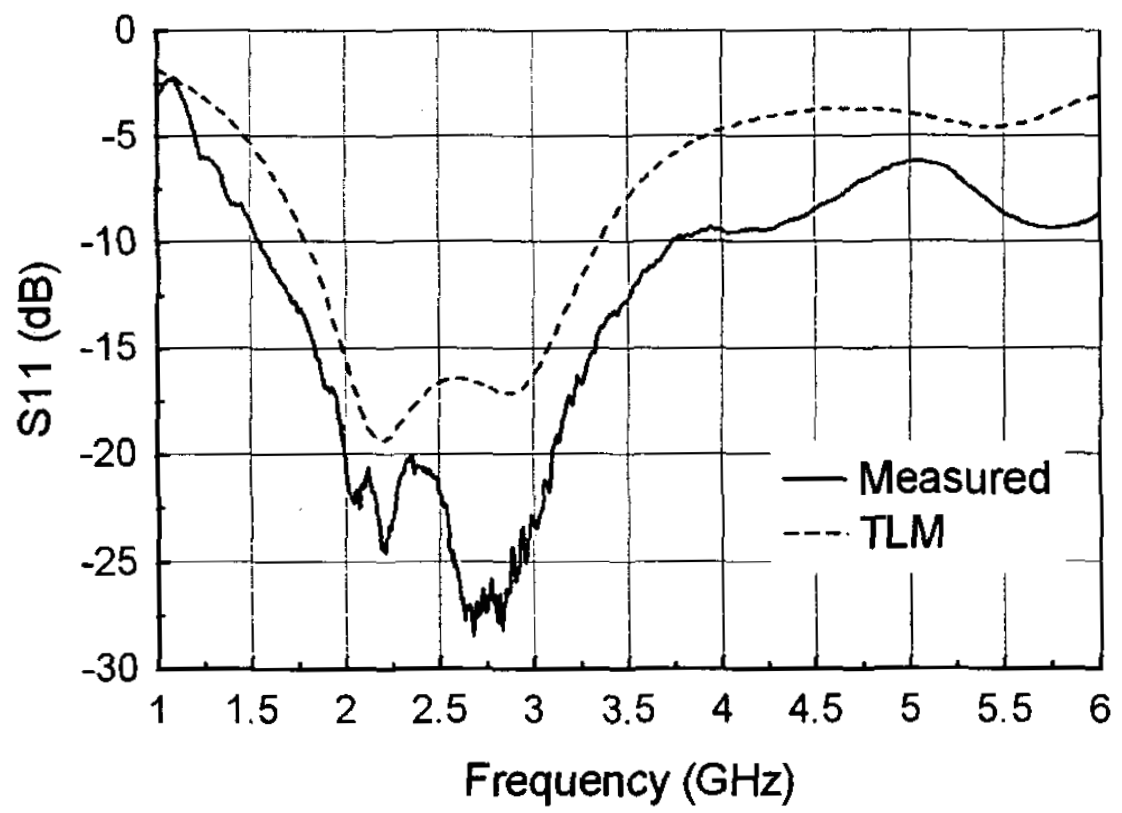

Figure 5: Comparison of simulated and measured results for the PMA.

\section{RADIATION CHARACTERISTICS}

The radiation characteristics for both the printed monopole and the EM-coupled monopole antennas are typically of monopole antennas with omnidirectional radiation in the azimuth plane and a figure-of-eight pattern in the elevation plane, with a null at the zenith. The radiation characteristics remain reasonably consistent over the $10 \mathrm{~dB}$ impedance bandwidth (keeping within $+/-2 \mathrm{~dB}$ ). Radiation patterns for the EM PMA antenna are shown in Fig. 6 and Fig. 7. 


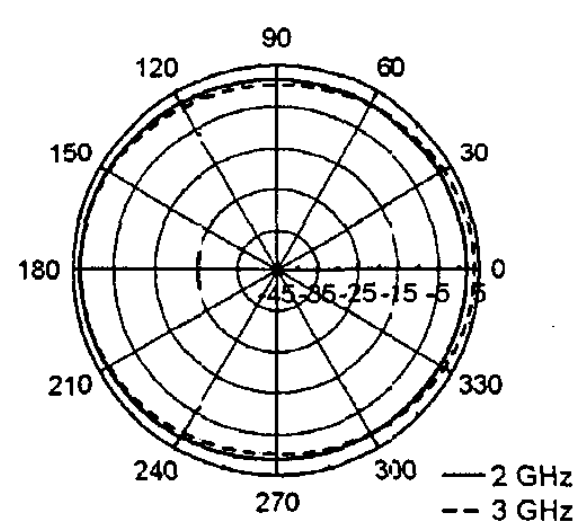

Figure 6: Radiation pattern for $\mathrm{E} \theta$ in the $\mathrm{x}-\mathrm{z}$ plane, at 2 and $3 \mathrm{GHz}$.

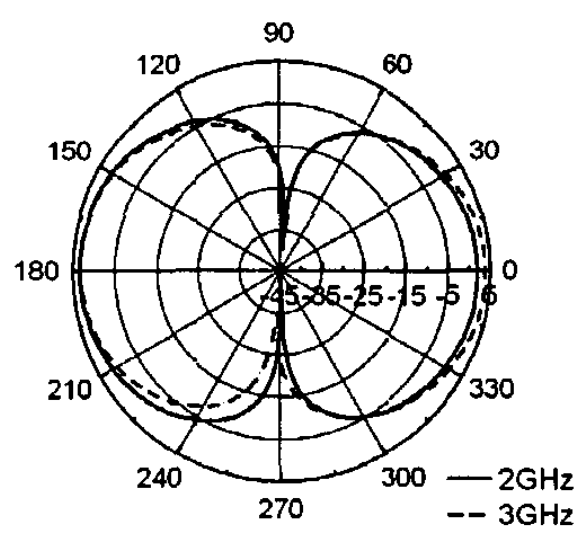

Figure 7: Radiation pattern for $\mathrm{E} \theta$ in the $\mathrm{y}-\mathrm{z}$ plane, at 2 and $3 \mathrm{GHz}$.

\section{CONCLUSION}

The addition of an electromagnetically coupled slotted element to a printed monopole antenna has been shown to reduce the lower edge frequency of the $10 \mathrm{~dB}$ impedance bandwidth without affecting the radiation characteristics, which remain monopolar. The slotted EM coupled antenna is shown to have a wide impedance bandwidth, with a low lower edge frequency from 1.26 to $2.42 \mathrm{GHz}$ and from 2.78 to $3.29 \mathrm{GHz}$, which represents a reduction of $18 \%$ over the printed monopole antenna. Optimisation of the location of the microstrip feed line is shown to increase the impedance bandwidth of the PMA by over $75 \%$, producing a wide bandwidth from 1.64 to $5.5 \mathrm{GHz}$. The wide impedance bandwidth, radiation characteristic, small size and low cost makes this type of antenna suitable for a number of modern mobile and portable applications such as cellular mobile and wireless LAN systems.

\section{REFERENCES}

[1] Chen, Z. N, Chia, M.Y.W., and Ammann, M.J., 'Optimization and Comparison of Broadband Monopoles', IEE Proceedings Microw. Antennas \& Propagat. 2003, 150, (6), 429-435

[2] Wu, Z, Sevret, P and Ammann M.J., 'Broadband Dual-Plate Monopole Antennas,' $12^{\text {th }}$ IEE International Conf. Antennas \& Propagat. 2003, Vol. (2) pp. 493-495

[3] Yeh, S.H. and Wong, K.L., 'Intefrated F-shaped Monopole Antenna for 2.4/5.2 GHz Dual Band Operation, 'Microw. Opt. Technol Lett. 2002, (34) 2426 